\title{
LIPÍDIOS EM SEDIMENTOS ARQUEOLÓGICOS - RESULTADOS PRELIMINARES DO SÍTIO ARQUEOLÓGICO RIO DO MEIO, ILHA DE SANTA CATARINA (SC) ${ }^{(1)}$
}

\author{
Fabrício Augusto Hansel ${ }^{(2)}$, Teresa Domitila Fossari ${ }^{(3)}$ \& Luiz \\ Augusto dos Santos Madureira ${ }^{(4)}$
}

\begin{abstract}
RESUMO
Este trabalho foi realizado com o objetivo de avaliar a distribuição de lipídios em sedimentos arqueológicos do sítio Rio do Meio, Ilha de Santa Catarina. Nos extratos totais de lipídios, analisados por cromatografia gasosa e espectrometria de massas (CG e CG-EM), predominaram os compostos ácidos e álcoois saturados. Foram detectados pelo menos dois tipos de matéria orgânica: uma antiga e outra comparativamente recente. Na primeira, o extrato total de lipídios foi dominado por ácidos graxos de cadeias curtas $\left(<\mathrm{Ac}_{20: 0}\right)$, com menor percentagem de ácidos $\mathrm{e}$ álcoois de cadeias longas ( $>\mathbf{A c}_{20: 0}$ e $\mathbf{A l}_{20: 0}$ ). Em contraste, na deposição classificada como recente, foram identificados em maiores teores os ácidos e álcoois de cadeias longas ( $>\mathrm{Ac}_{20: 0}$ e $\mathbf{A l}_{20: 0}$ ). Neste estudo, foi possível observar a incorporação de material orgânico procedente de fontes de origem vegetal, bacteriana e, possivelmente, animal (gorduras) nos sedimentos arqueológicos analisados.
\end{abstract}

Termos de indexação: biomarcadores, arqueologia, geoquímica orgânica.

\section{SUMMARY: LIPIDS IN ARCHAEOLOGICAL SEDIMENTS - PRELIMINARY RESULTS OF THE ARCHAEOLOGICAL SITE RIO DO MEIO, SANTA CATARINA ISLAND (SC), BRAZIL}

In this study the distribution of lipid compounds was evaluated in sediment samples of an archaeological site Rio do Meio, Santa Catarina Island, Brazil. In the total lipid extracts, analyzed by gas chromatography and mass spectrometry (GC and $G C-M S)$,

\footnotetext{
(1) Parte do trabalho de Tese de Doutorado em química analítica, Universidade Federal de Santa Catarina - UFSC. Programa de pós-graduação em química. Recebido para publicação em julho de 2005 e aprovado em agosto de 2007.

(2) Analista A, Embrapa/CNPF. Estrada da Ribeira km 111, Guaraituba, CEP 83410-000 Colombo (PR). E-mail: hansel@cnpf.embrapa.br

(3) Arqueóloga do Museu Universitário Professor Oswaldo Rodrigues Cabral, Universidade Federal de Santa Catarina - UFSC. CEP 88040-900 Florianópolis (SC). E-mail: teresafo@hotmail.com

(4) Professor Adjunto do Departamento de Química, UFSC. E-mail: madureira@qmc.ufsc.br
} 


\begin{abstract}
saturated fatty acids and alcohols were predominant. At least two sources of organic matter were detected, an older and a more recent one. In the old deposit, the most abundant lipids were short-chain fatty acids $\left(<A c_{20: 0}\right)$, followed by a minor composition of long-chain fatty acids and alcohols ( $>A c_{20: 0}$ and $A l_{20: 0}$ ). In contrast, the fresh deposit was dominated by long-chain fatty acids and alcohols $\left(>A c_{20: 0}\right.$ and $\left.A l_{20: 0}\right)$. This paper described the incorporation of vegetal, bacterial and possible animal (fat) sources into the archaeological sediments analyzed.
\end{abstract}

Index terms: archaeology, biomarkers, organic geochemistry.

\section{INTRODUÇÃO}

A geoquímica orgânica usa conceitos da química, da geoquímica dos fósseis e dos marcadores biológicos (biomarcadores) para interpretar os resíduos orgânicos preservados em rochas sedimentares, na tentativa de encontrar seus possíveis precursores biológicos (Eglinton \& Calvin, 1967). A composição química da matéria orgânica de solos e sedimentos marinhos tem sua origem basicamente nas seguintes fontes: fitoplâncton, zooplâncton, bactérias, fungos e plantas superiores, além de uma pequena contribuição animal. Entre as classes principais dos compostos detectados, (DNA, carboidratos, proteínas, lipídios e ligninas), os lipídios destacam-se por apresentar maior resistência à degradação quando comparados às outras classes, além de também fornecer um diagnóstico do material depositado (Mackenzi et al., 1982; Tissot \& Welte, 1984; Eglinton \& Logan, 1991).

A matéria orgânica do solo tem como características a heterogeneidade, a transiência e a suscetibilidade às variações das condições redox, lixiviação e erosão (Hedges \& Oades, 1997). Com a contínua reciclagem do material proveniente de plantas (folhas, galhos e raízes), a matéria orgânica do solo é constantemente renovada, sendo freqüentemente encontradas as classes de lipídios que caracterizam resíduos de plantas, atividade bacteriana, microflora e microfauna (Goossens et al., 1986; Amblès et al., 1989, 1993, 1994; Dinel et al., 1990; Jambu et al., 1991, 1993, 1995; Hita et al., 1996; van Bergen et al., 1997, 1998; Bull et al., 1998, 2000a,b; Nierop, 1998). Embora a transiência seja uma característica marcante, os solos possuem mecanismos positivos à preservação da matéria orgânica, como a adsorção em diferentes frações (argila, ácidos húmicos e ácidos fúlvicos), e à formação de agregados (Guggenberger \& Zech, 1999; Kaiser \& Guggenberger, 2000; Bastos et al., 2005). A preservação da matéria orgânica em solos é fator preponderante em trabalhos arqueológicos, pois, com a identificação de certas classes de compostos químicos preservados (e.g. lipídios), é possível relatar a história do ambiente de deposição e, assim, demonstrar tanto a transição de diferentes vegetações como também uma possível interferência humana.

A análise de lipídios de sedimentos e solos arqueológicos não é um assunto muito explorado. Uma das aplicações proeminentes é a avaliação de biomarcadores fecais (e.g. $5 \beta$-estanóis), seja no processo de adubação orgânica de solos arqueológicos ou na composição dos locais de rejeitos (Bethell et al., 1994; Simpson et al., 1998; Bull et al., 1999a,b e 2003). Com relação a estudos envolvendo sedimentos/solos arqueológicos brasileiros, nestes evidenciam-se os trabalhos sobre a terra preta arqueológica (TPA), nos quais se percebe uma abordagem com ênfase na fase mineral (inorgânica) do solo (Kern \& Kämpf, 1989; Kern, 1996). A parte orgânica, contudo, tem recebido menor atenção, onde dados de $\mathrm{C}$ orgânico total (COT) e de "black carbon" (partículas de C produzidas por combustão e que possuem uma microestrutura grafítica) foram avaliados (Kern, 1996; Glaser et al., 2000).

O material orgânico e inorgânico de determinado sítio arqueológico reflete tanto aspectos culturais (ações antrópicas) como não-culturais (e.g. vegetação) (Shiffer, 1987). A potencialidade da aplicação do estudo dos lipídios é indiscutível, visto o possível diagnóstico dos diferentes tipos de vegetação que contribuíram na formação do sítio arqueológico e, ou, da atividade antrópica durante a ocupação e exploração da área pelos grupos ali assentados (van Bergen et al., 1997; Evershed et al., 1997). Este trabalho foi realizado com os objetivos de avaliar a distribuição dos lipídios e investigar qualitativamente a origem da matéria orgânica depositada em sedimentos arqueológicos do sítio Rio do Meio, Ilha de Santa Catarina, SC.

\section{MATERIAL E MÉTODOS}

O sítio Rio do Meio foi representado por uma área total de $448 \mathrm{~m}^{2}$, formada por duas subáreas (área I e área II). O sítio estava assentado sobre sedimentos arenosos holocênicos, junto à praia de Jurerê e à baía ampla (Baía Norte), quase no norte da Ilha de Santa Catarina ( $48^{\circ} 30$ ' oeste e $27^{\circ} 30$ ' sul). A área II foi datada de 1170 d.C.; por meio da técnica de ${ }^{14} \mathrm{C}$ (Fossari, 2004). O sítio Rio do Meio está relacionado à população pré-colonial Jê, que ocupou a costa catarinense a partir dos séculos IX ou X d.C., nela permanecendo até mais ou menos o século XV.

As amostras de sedimento são provenientes de escavações arqueológicas da área II, a qual foi dividida 
horizontalmente em quadras (Q) de $1 \mathrm{~m}^{2}$ de área, identificadas por uma letra e um número. Na dimensão vertical, as camadas arqueológicas ou níveis $(\mathrm{N})$ variaram de 5 a $10 \mathrm{~cm}$ de espessura, sendo cada um identificado por um número. As amostras foram coletadas de três quadras com diferentes níveis, denominados contextos (QF18/N5, QK22/N2 e QQ21/ N3); todos apresentaram um etnoestrato com restos faunísticos (ossos e, ou, conchas), mas somente o contexto QF18/N5 continha núcleos de carvão. Os contextos QF18/N5, QK22/N2 e QQ21/N3 encontravamse nas profundidades aproximadas de 50, 20 e $30 \mathrm{~cm}$, respectivamente.

O método utilizado na extração dos lipídios está descrito em Hansel et al. (2006). Os lipídios foram extraídos de cerca de 5,0 g de sedimento seco $\left(60^{\circ} \mathrm{C}\right.$, $24 \mathrm{~h})$ e peneirado $(0,5 \mathrm{~mm})$ com a mistura de solvente $\mathrm{CHCl}_{3}: \mathrm{CH}_{3} \mathrm{OH}(2: 1 \mathrm{v} / \mathrm{v}, 10 \mathrm{~mL}, 2$ x 15 min no ultrasom). Os extratos foram combinados após serem centrifugados (25 min, $2.500 \mathrm{rpm}$ ) e secos sob leve fluxo de $\mathrm{N}_{2}$. Os extratos dissolvidos em $1 \mathrm{~mL}$ de tolueno foram esterificados com uma solução de $\mathrm{MeOH}$ :cloreto de acetila (9:1 v/v, $\left.2 \mathrm{~mL}, 60^{\circ} \mathrm{C}, 12 \mathrm{~h}\right)$. Após adição de $1 \mathrm{~mL}$ de solução aquosa de $\mathrm{KCl}(10 \% \mathrm{~m} / \mathrm{v})$, o extrato orgânico foi extraído com $\mathrm{CHCl}_{3}(3 \times 1 \mathrm{~mL})$. Os extratos combinados tiveram o seu volume reduzido a $1 \mathrm{~mL}$. Em seguida, a água residual foi retirada, passando-se a solução por uma minicoluna de vidro $(10 \times 0,5 \mathrm{~cm})$ contendo sulfato de sódio anidro calcinado $\left(400{ }^{\circ} \mathrm{C}, 2 \mathrm{~h}\right)$. $\mathrm{O}$ extrato orgânico foi recolhido em um frasco $(3 \mathrm{~mL}) \mathrm{e}$ seco sobre um fluxo de $\mathrm{N}_{2}$. Os extratos esterificados foram então silanizados (40 $\left.\mu \mathrm{L} \mathrm{BSTFA,} 70{ }^{\circ} \mathrm{C}, 1 \mathrm{~h}\right)$; posteriormente, o excesso de BSTFA foi evaporado sob um fluxo de $\mathrm{N}_{2}$. Os extratos dissolvidos em $80 \mu \mathrm{L}$ de hexano foram analisados por cromatografia gasosa (CG) e cromatografia gasosa acoplada à espectrometria de massas (CG-EM) em até $24 \mathrm{~h}$. O volume injetado foi de $1 \mu \mathrm{L}$, utilizando o modo splitless (30 s). As quantificações foram realizadas no CG com o método de padronização interna, utilizando como padrão $30 \mu \mathrm{g}$ de $5 \alpha$-colestano (desvio-padrão relativo $\pm 5,9 \%$ ).

Os índices preferenciais de C (IPC) para os compostos ácidos e álcoois saturados foram determinados a partir da área do pico fornecido pela CG, por meio da equação (Cooper \& Bray, 1963):

IPC $=2\left(\Sigma\right.$ pares $\mathrm{C}_{22}$ a $\left.\mathrm{C}_{30}\right):\left[\left(\Sigma\right.\right.$ ímpares $\mathrm{C}_{21}$ a $\left.\mathrm{C}_{29}\right)+$ ( $\Sigma$ ímpares $\mathrm{C}_{23}$ a $\mathrm{C}_{31}$ )]

no qual $\mathrm{C}_{\mathrm{x}}$ são os compostos ácidos ou álcoois e x é o número de átomos de $\mathrm{C}$ na molécula.

As análises por cromatografia gasosa (CG) foram realizadas no aparelho da marca Shimadzu (GC-17A) com detector por ionização em chama, injetor split/ splitless e gás de arraste $\mathrm{N}_{2}$. As análises por cromatografia gasosa acoplada à espectrometria de massas (CG-EM) foram realizadas em um equipamento da marca Shimadzu (GC-MS-QP2000 A) acoplado a um cromatógrafo gasoso da marca Shimadzu (GC-14B) com injetor split/splitless. O gás de arraste utilizado foi o hélio. Coluna cromatográfica usada: CBP1 (25 m x 0,32 mm, 0,25 $\mu \mathrm{m}$ ); programação do forno do CG: temperatura inicial: $40^{\circ} \mathrm{C}$; taxa de aquecimento: $10^{\circ} \mathrm{C} \min ^{-1}$ até $150{ }^{\circ} \mathrm{C}$, então $4{ }^{\circ} \mathrm{C} \mathrm{min}{ }^{-1}$ até $310^{\circ} \mathrm{C}$; e isoterma de $10 \mathrm{~min}$.

A análise de C orgânico total (COT) (desvio-padrão relativo $\pm 0,3 \%$ ) foi realizada no aparelho Carlo Erba EA-1100. O teor de COT das amostras do sedimento foi determinado após descarbonatação $\left(2,0 \mathrm{~mol} \mathrm{~L}^{-1} \mathrm{de}\right.$ $\mathrm{HCl})$ e secagem $\left(60^{\circ} \mathrm{C}, 12 \mathrm{~h}\right)$.

\section{RESULTADOS E DISCUSSÃO}

Os contextos QF18/N5, QK22/N2 e QQ21/N3 apresentaram caráter alcalino, o qual está possivelmente associado à significativa quantidade de conchas e à proximidade com o mar ( $\mathrm{pH}_{\text {água marinha }} \approx 7$ ) (Quadro 1). Já o teor de matéria orgânica é baixo quando comparado ao de outros ambientes de deposição da mesma região, como manguezais e lagoas (Zwirtes, 2003; Mater et al., 2004). Isso pode ser reflexo da característica arenosa do sedimento, a qual está associada ao baixo teor de matéria orgânica (Hedges \& Oades, 1997).

Quadro 1. Teores de lipídios, álcoois, ácidos, carbono orgânico total (COT) e índice preferencial de carbono para álcoois $\left(\mathrm{IPC}_{\mathrm{Al}}\right)$ e ácidos $\left(\mathrm{IPC}_{\mathrm{Ac}}\right)$ de amostras de sedimento dos três contextos do Sítio Arqueológico do Rio do Meio, Ilha de Santa Catarina (SC)

\begin{tabular}{|c|c|c|c|c|c|c|c|}
\hline Contexto & $\mathbf{p} \mathbf{H}^{(1)}$ & COT & Lipídios & Álcoois & IPCAl & Ácidos & IPCAc \\
\hline & & $\%$ & \multicolumn{2}{|c|}{$\mu \mathrm{g} \mathrm{g}^{-1}$} & \multicolumn{3}{|c|}{$\mu \mathrm{g} \mathrm{g}^{-1}$} \\
\hline QF18/N5 & 8,45 & 0,9 & 667 & 119 & 14 & 197 & 5 \\
\hline $\mathrm{QK} 22 / \mathrm{N} 2$ & 8,74 & $<0,1$ & 85 & 12 & 11 & 41 & 4 \\
\hline QQ21/N3 & 7,44 & 1,0 & 423 & 62 & 15 & 224 & 15 \\
\hline
\end{tabular}

(1) $\mathrm{O} \mathrm{pH}$ foi medido, após peneirar a $0,5 \mathrm{~mm}$, em água (sedimento: $\mathrm{H}_{2} \mathrm{O}$ 1:2,5). 
A concentração dos lipídios nos sedimentos variou de 85 a $667 \mu \mathrm{g} \mathrm{g}^{-1}$. Os extratos foram dominados por compostos ácidos (QF18/N5 - $29 \%$, QK22/N2 - $48 \%$ e QQ21/N3 - 52 \%) e álcoois (QF18/N5 - $18 \%$, QK22/ $\mathrm{N} 2$ - $14 \%$ e QQ21/N3 - $15 \%$ ) de cadeias saturadas (Quadro 1). Os ácidos e álcoois foram determinados a partir de seus espectros de massas característicos, para os ácidos na forma de ésteres metílicos e os álcoois na forma de trimetilsilil éteres. Os fragmentos característicos dos ácidos saturados (na forma ésteres metílicos) são o íon molecular $\mathrm{M}^{+}$, o fragmento $\mathrm{m} / \mathrm{z}=$ $74\left(\left(\mathrm{C}_{3} \mathrm{H}_{6} \mathrm{O}_{2}\right)^{+}\right.$- rearranjo de McLafferty) e o $\mathrm{m} / \mathrm{z}=87$ $\left(\mathrm{C}_{4} \mathrm{H}_{7} \mathrm{O}_{2}\right)^{+}$. Já para os álcoois saturados (na forma trimetilsilil éteres) os fragmentos característicos são o $\mathrm{m} / \mathrm{z}=75\left(\left(\mathrm{CH}_{3}\right)_{2} \mathrm{SiOH}\right)^{+}$e o $(\mathrm{M}-15)^{+}$massa molar menos uma metila $\left(\mathrm{CH}_{3}\right)$ do grupo trimetilsilil $\left.\left[\left(\mathrm{CH}_{3}\right)_{3} \mathrm{Si}\right]\right\}$ (Figura 1).

Entre os contextos, os valores de $\mathrm{IPC}_{\mathrm{Al}}$ para os álcoois são mais próximos entre si do que no caso dos ácidos, nos quais o $\mathrm{IPC}_{\mathrm{Ac}}$ do QQ21/N3 é superior ao dos contextos QK22/N2 e QF18/N5 (Quadro 1). Os valores de IPC indicam predomínio de compostos com número de átomos de $\mathrm{C}$ pares em relação aos ímpares, característica esta observada em plantas superiores, sugerindo incorporação de resíduos de plantas nos sedimentos (Jambu et al., 1993; Amblès et al., 1994). A diminuição do $\mathrm{IPC}_{\mathrm{Ac}}$ para os ácidos nos contextos QK22/N2 e QF18/N5 indica que essas substâncias foram influenciadas por importantes mudanças durante os processos de decomposição e humificação dos resíduos de plantas e, portanto, caracteriza um material em processo de diagênese adiantado. A diminuição do IPC ocorre devido a aumento da concentração relativa dos ácidos com cadeia alquílica ímpares sobre os ácidos pares, o que pode ser um reflexo da oxidação terminal dos hidrocarbonetos saturados presentes no ambiente. Esta característica é encontrada em solos humificados e desenvolvidos, portanto mais antigos. Em valores, camadas recentes de solos apresentam IPC altos, e estes refletem os valores encontrados nas ceras epicuticulares $\left(\mathrm{IPC}_{\mathrm{Ac}}>10\right)$, os quais gradativamente diminuem à medida que o horizonte do solo sofre com processos de degradação e humificação ( $\operatorname{IPC}_{\mathrm{Ac}}<10$ ), por exemplo, da serrapilheira para o horizonte A1 (Jambu et al., 1993; Amblès et al., 1994; Bull et al., 1999a). Os altos valores de $\mathrm{IPC}_{\mathrm{Al}}$ para os álcoois, nos contextos $\mathrm{QF} 18 / \mathrm{N} 5$ e QK22/N2, podem ser atribuídos à maior resistência à degradação, ou ainda a uma fonte alternativa recente para eles, os quais não foram de maneira significativa alterados pelos processos de decomposição. Desse modo, nos contextos QF18/N5 e QK22/N2, os dados de IPC $\mathrm{Ac}_{\mathrm{Ac}}$ sugerem sedimentos mais antigos quando comparado ao contexto QQ21/N3 (Quadro 1), abrindo a possibilidade de se tratar de um solo formado na época do assentamento do grupo précolonial. Já os altos valores dos $\mathrm{IPC}_{\mathrm{Al}}$ e IPC $\mathrm{IPc}_{\mathrm{Ac}}$ apresentados no contexto QQ21/N3 sugerem uma fonte recente e diferente daquelas dos contextos QK22/ N2 e QF18/N5 (Quadro 1).

Na figura 2 são apresentados os histogramas das percentagens relativas dos ácidos e álcoois identificados nos sedimentos estudados. Diferenças qualitativas podem ser observadas entre os contextos QK22/N2 e QF18/N5 contra o contexto QQ21/N3. Os dois primeiros apresentam maior percentagem relativa de ácidos graxos com números de átomos de $\mathrm{C}$ inferiores a 20, com máximos nos ácidos palmítico $\left(\mathrm{Ac}_{16: 0}\right) \mathrm{e}$ esteárico $\left(\mathrm{Ac}_{18: 0}\right)$. O último QQ21/N3 tem como composto majoritário o ácido docosanóico $\left(\mathrm{Ac}_{22: 0}\right)$ (Figura 2a). Com relação à distribuição dos ácidos graxos acima de 20 átomos de $\mathrm{C}$, percebe-se também semelhança entre os contextos QK22/N2 e QF18/N5, nos quais não existe um composto majoritário em destaque, sendo os compostos com 22 e 24 átomos de carbono predominantes (Figura 2a). A distribuição dos álcoois (Figura 2b) apresenta o mesmo comportamento dos ácidos: os contextos QK22/N2 e QF18/N5
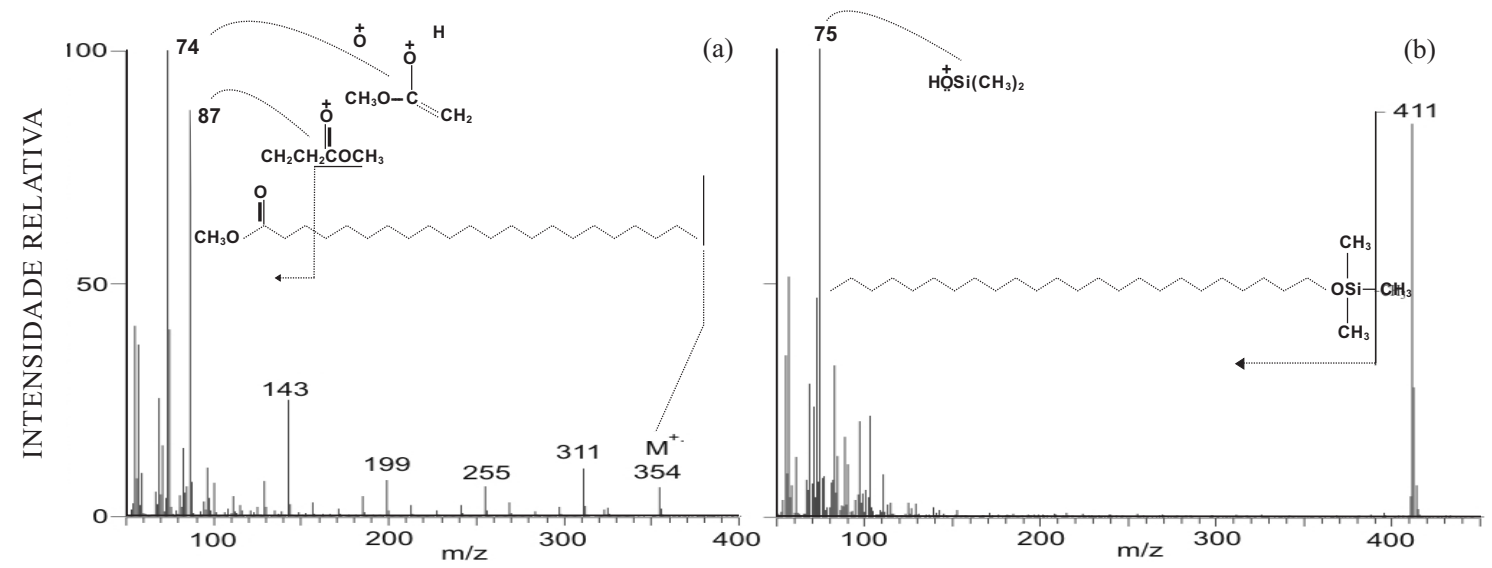

Figura 1. Espectro de massas exemplificando a identificação dos ácidos e álcoois saturados nas amostras de sedimento. Ácido docosanóico (a) e álcool tetracosanol (b), nas formas de éster metílico e trimetilsilil éter, respectivamente. 
assemelham-se entre si e diferem do contexto QQ21/ N3. Neste contexto, o composto majoritário é o álcool tetracosanol $\left(\mathrm{Al}_{24: 0}\right)$, o que não é percebido nos demais contextos, nos quais existe distribuição semelhante nos álcoois com 22, 24, 26, 28 e 30 átomos de C (Figura 2b). Esses resultados corroboram os dados de IPC para ácidos e álcoois quando se afirma haver duas fontes distintas: uma depositada nos contextos QF18/N5 e QK22/N2 e outra no contexto QQ21/N3.

Os ácidos e álcoois saturados detectados nos contextos QF18/N5 e QK22/N2 são na maioria pertencentes a plantas superiores (ceras epicuticulares), mostrando a incorporação de resíduos vegetais no sedimento (Kolattukudy, 1980). Entretanto, a presença dos ácidos graxos com menos de 20 átomos de $\mathrm{C}\left(<\mathrm{Ac}_{20: 0}\right)$ e do colesterol, identificado pelo seu espectro de massas na forma trimetilsilil éter $\left(\mathrm{M}^{+} 458\right.$, $\mathrm{m} / \mathrm{z} 129, \mathrm{~m} / \mathrm{z} 329, \mathrm{~m} / \mathrm{z} 353, \mathrm{~m} / \mathrm{z} 368, \mathrm{~m} / \mathrm{z} 443, \mathrm{~m} / \mathrm{z}$ 458 ), pode estar associada a outras fontes.

No contexto QF18/N5, os ácidos graxos $<\mathrm{Ac}_{20: 0}$ podem ter sua origem em gorduras de animais, uma vez que nele foram constatados restos faunísticos e marcas de carvão, sugerindo um fogão. No entanto, esses compostos não são biomarcadores específicos, mas amplamente distribuídos na natureza, e podem tanto ter origem animal (gordura), vegetal ou bacteriana (Goossens et al., 1986; Amblès et al., 1994; Hita et al., 1996). Do mesmo modo que a presença do colesterol pode ser indicativo da deposição de gordura, este também pode ter sido sintetizado por artrópodes a partir de outros esteróis detectados na amostra, como o $\beta$-sitosterol (na forma trimetilsilil éter: $\mathrm{M}^{+} 486$, $\mathrm{m} / \mathrm{z} 129, \mathrm{~m} / \mathrm{z} 357, \mathrm{~m} / \mathrm{z} 381, \mathrm{~m} / \mathrm{z} 396, \mathrm{~m} / \mathrm{z} 471$ ) identificado no extrato lipídico (Svoboda \& Thompson, 1985; Nes et al., 1997). Já os ácidos ramificados iso e anteiso pentadecanóico e heptadecanóico $\left(\mathrm{Ac}_{15: 0 \mathrm{r}} \mathrm{e}\right.$ $\mathrm{Ac}_{17: 0 \mathrm{r}}$, identificados no contexto, indicam a atividade bacteriana no sedimento, uma vez que eles são abundantes nas membranas celulares de certas bactérias (Figura 2a) (Goossens et al., 1986).

No contexto QQ21/N3, verifica-se um depósito de matéria orgânica classificada como recente (Figura 3), sugerido pelos altos valores dos IPC para ácidos e álcoois (Quadro 1). As distribuições dos ácidos e álcoois $\left(>\mathrm{C}_{20: 0}\right)$ refletem a deposição de plantas superiores (Kolattukudy, 1980; Walton, 1990), mas com origem diferente da dos contextos QK22/N2 e QF18/N5. Isso é reforçado pelas distribuições dos álcoois e ácidos, presença dos compostos $\omega$-hidroxiácidos com cadeias carbônicas superiores a 20 átomos, presença de um derivado do ácido cinâmico, ausência do colesterol e menor abundância relativa dos ácidos graxos menores que 20 átomos de $\mathrm{C}$ (Figuras 2 e 3 ).

Os $\omega$-hidroxiácidos foram identificados a partir de seus espectros de massas característicos na forma de éster metílicos e trimetilsilil éter $(\mathrm{m} / \mathrm{z} 75$ $\left(\left(\mathrm{CH}_{3}\right)_{2} \mathrm{SiOH}^{+}\right), \mathrm{m} / \mathrm{z} 146\left(\mathrm{C}_{6} \mathrm{H}_{14} \mathrm{SiO}_{2}{ }^{+}\right), \mathrm{M}^{+} .15$ e $\mathrm{M}^{+}$ -47). A origem deles em solos está associada tanto à $\omega$-oxidação dos ácidos graxos saturados (Hita et al., 1996) como à despolimerização de tecidos vegetais (cutina e suberina) (Kolattukudy, 1980; Walton, 1990). Considerando o alto valor do $\mathrm{IPC}_{\mathrm{Ac}}$ e nenhuma correlação entre os ácidos graxos e os $\omega$-hidroxiácidos (os compostos predominantes são o ácido graxo $\mathrm{Ac}_{22: 0}$ e o ácido $\omega$-hidroxi-hexacosanóico, $\omega$ - $\mathrm{HAc}_{26: 0}$ ), a $\omega$-oxidação dos ácidos graxos saturados não é sustentada. Por sua vez, a hipótese da despolimerização de tecidos vegetais, mais especificamente da suberina, é reforçada pela presença de um derivado do ácido cinâmico, especificamente o ácido cinâmico 4-etenil2-metoxi-fenol (Figura 3).

A suberina possui estrutura polimérica formada por ligações cruzadas envolvendo estruturas do tipo poliaromática (ácido cinâmico e seus derivados) e polialifática (monômeros alifáticos comportando ácidos graxos de cadeias longas (>20), $\omega$-hidroxiácidos, dihidroxiácidos, tri-hidroxiácidos e epoxiácidos) (Kolattukudy, 1980; Walton, 1990; Bull et al., 2000b; Naafs \& van Bergen, 2002). Mesmo que os demais compostos da estrutura polimérica alifática não tenham sido identificados, a deposição classificada como recente e a profundidade do contexto QQ21/N3 (aproximadamente $30 \mathrm{~cm}$ ) apontam como sua origem a suberina (associada, no caso, a raízes).
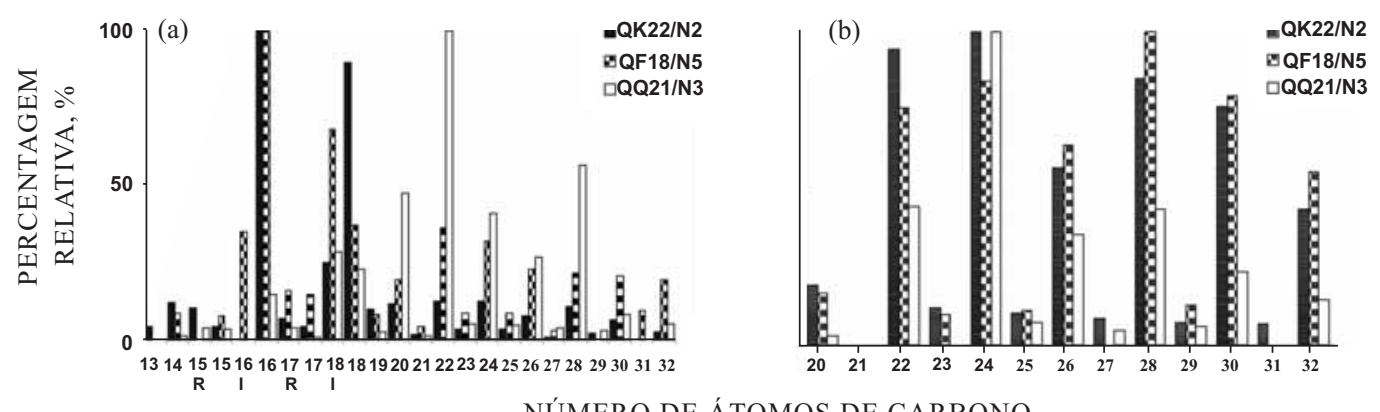

NÚMERO DE ÁTOMOS DE CARBONO

Figura 2. Histogramas da distribuição percentual de compostos ácidos (a) e álcoois (b) de amostras de sedimento dos três contextos do Sítio Arqueológico do Rio do Meio, Ilha de Santa Catarina, SC. R: compostos ramificados (iso e anteiso) e I: compostos monoinsaturados. 


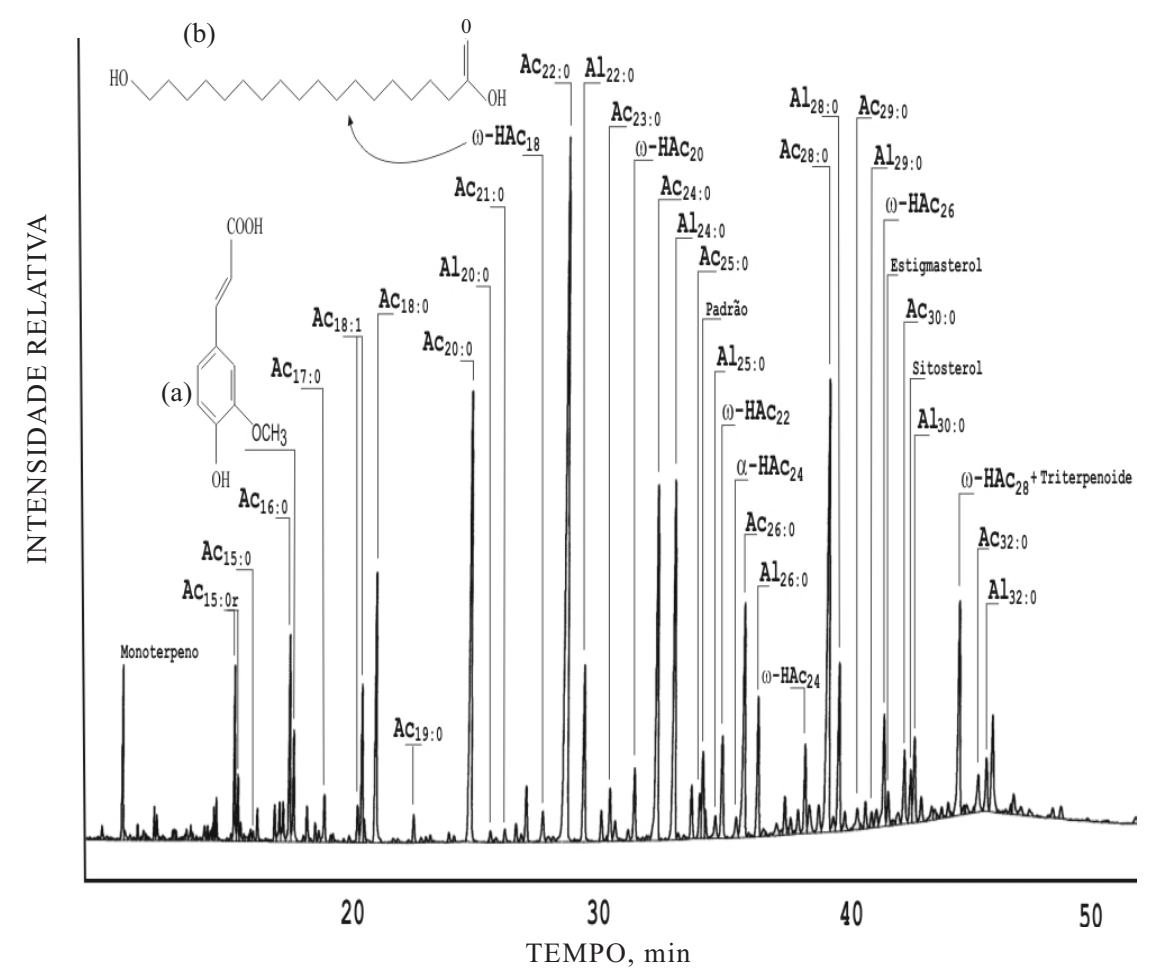

Figura 3. Cromatograma parcial da amostra de sedimento obtida no contexto QQ21/N3 do Sítio Arqueológico Rio do Meio, Ilha de Santa Catarina, SC. Em destaque as estruturas de um derivado do ácido cinâmico (a) e de um $\omega$-hidroxiácido (b). $\mathrm{Ac}_{\mathrm{x}: \mathrm{y}}$ e $\mathrm{Al}_{\mathrm{x}: \mathrm{y}}$, respectivamente ácidos e álcoois; $\mathrm{x}$, número de átomos de carbono; $y$, número de insaturações; $\omega$-HAc ${ }_{x}$, hidroxiácidos com a hidroxila na posição $\omega$; padrão, $5 \alpha$-colestano.

A ausência do colesterol (mesmo com a presença de outros esteróis) e a baixa presença dos ácidos graxos $\mathrm{Ac}_{16: 0}$ e $\mathrm{Ac}_{18: 0}$, no contexto QQ21/N3, contribui para especulação de uma fonte de origem animal (gordura) para esses compostos nos outros dois contextos (QF18/ N5 e QK22/N2). Já os outros esteróis detectados no extrato de lipídios do contexto QQ21/N3 estigmasterol (na forma trimetilsilil éter: $\mathrm{M}^{+} .484$, $\mathrm{m} / \mathrm{z} 129, \mathrm{~m} / \mathrm{z} 255, \mathrm{~m} / \mathrm{z} 379, \mathrm{~m} / \mathrm{z} 394, \mathrm{~m} / \mathrm{z} 469)$ e $\beta$ sitosterol - não auxiliam na determinação de uma fonte específica, uma vez que são comumente detectados em extratos de plantas. A presença dos ácidos graxos $<\mathrm{Ac}_{20: 0}$, principalmente dos ácidos graxos iso e anteiso pentadecanóicos $\left(\mathrm{Ac}_{15: 0 \mathrm{r}}\right)$, é indicativo da atividade bacteriana nesse contexto (Figuras 2a e 3).

\section{CONCLUSÕES}

1. A composição orgânica dos sedimentos do Sítio Rio do Meio tem origem vegetal, bacteriana e, possivelmente, animal (gorduras).

2. Os extratos de lipídios apresentaram compostos ácidos e álcoois saturados característicos de plantas superiores.
3. Detectou-se pelo menos duas fontes de matéria orgânica: uma antiga e outra recente. A antiga foi dominada por ácidos graxos de cadeia curta $\left(<\mathrm{Ac}_{20: 0}\right)$ com menor percentagem dos ácidos e álcoois de cadeias longas ( $>\mathrm{Ac}_{20: 0}$ e $\mathrm{Al}_{20: 0}$ ), e a recente apresentou os ácidos e álcoois de cadeia longa $\left(>\mathrm{Ac}_{20: 0}\right)$ como compostos majoritários.

4. Não foi possível definir se a origem da matéria orgânica do sedimento está associada à ação antrópica (de ordem cultural) ou não.

\section{TRABALHOS FUTUROS}

O estudo do sedimento ou solo arqueológico do ponto de vista demonstrado neste trabalho abre novas perspectivas de análises para compreensão da formação de um sítio arqueológico, sejam as variáveis envolvidas de ordem cultural ou não. Em trabalhos futuros, deverão ser buscadas contribuições interdisciplinares (e.g., arqueologia, química, agronomia) para ampliar o quadro das investigações sobre a formação de um sítio arqueológico. A aplicação de técnicas específicas dessas disciplinas e de número maior de amostras de estruturas arqueológicas 
reconhecidas (i.é., vestígios de expedientes funcionais, como fogueiras de cozinhas, marca de solos de cabanas e locais de descarte de resíduos de atividades domésticas) possibilitará estudos com mais detalhes, como por exemplo, a avaliação de outros biomarcadores, como os $5 \beta$-estanóis e os ácidos biliares, e uma comparação dos extratos de lipídios de sedimentos com vegetação que cobria o sítio nas fases recentes.

\section{AGRADECIMENTOS}

Ao CNPq, pela concessão de auxílio financeiro; à R. Strelau, pela assistência técnica; e aos revisores e editor anônimos, pelas sugestões no corpo do trabalho.

\section{LITERATURA CITADA}

AMBLÈS, A.; JAMBU, P.; JACQUESY, J.C.; PARLANTI, E. \& SECOUET, B. Changes in the ketone portion of lipidic components during the decomposition of plant debris in a hydromorphic forest-podzol. Soil Sci., 156:49-56, 1993.

AMBLÈS, A.; JAMBU, P.; PARLANTI, E.; JOFFRE, J. \& RIFFE, C. Incorporation of natural monoacids from plant residues into an hydromorphic forest podzol. Eur. J. Soil Sci., 45:175-182, 1994.

AMBLÈS, A.; MAGNOUX, P.; JAMBU, P.; JACQUESY, J.C. \& FUSTEC, E. Effect of addition of bentonite on the hydrocarbon fraction of a podzol soil (A1 Horizon). J. Soil Sci., 40:685-694, 1989.

BASTOS, R.S.; MENDONÇA, E.S.; ALVAREZ V., V.H. \& CÔRREA, M.M. Formação e estabilização de agregados do solo decorrentes da adição de compostos orgânicos com diferentes características hidrofóbicas. R. Bras. Ci. Solo, 29:11-20, 2005.

BETHELL, P.H.; GOAD, L.J.; EVERSHED, R.P. \& OTTAWAY, J. The study of molecular markers of human activity: The use of coprostanol in the soil as an indicator of human faecal material. J. Archaeol. Sci., 21:619-632, 1994.

BULL, I.D.; ELHMMALI, M.M.; ROBERTS, D.J. \& EVERSHED, R.P. The application of steroidal biomarkers to track the abandonment of a roman wastewater course at the Agora (Athens, Greece). Archaeometry, 45:149$161,2003$.

BULL, I.D.; NOTT, C.J.; van BERGEN, P.F.; POULTON, P.R. \& EVERSHED, R.P. Organic geochemical studies of soils from the Rothamsted classical experiments - VI. The occurrence and source of organic acids in an experimental grassland soil. Soil Biol. Biochem., 32:1367-1376, 2000b.

BULL, I.D.; SIMPSON, I.A.; DOCKRILL, S.J. \& EVERSHED, R.P. Organic geochemical evidence for the origin of ancient anthropogenic soil deposits at Tofts Ness, Sanday, Orkney. Org. Geochem., 30:535-556, 1999a.
BULL, I.D.; SIMPSON, I.A.; van BERGEN, P.F. \& EVERSHED, R.P. Muck 'n' molecules: Organic geochemical methods for detecting ancient manuring. Antiquity, 73:86-96, $1999 \mathrm{~b}$.

BULL, I.D.; van BERGEN, P.F.; NOTT, C.J.; POULTON, P.R. \& EVERSHED, R.P. Organic geochemical studies of soils from the Rothamsted classical experiments. V - The fate of lipids in different long-term soil experiments. Org. Geochem., 31:389-408, 2000a.

BULL, I.D.; van BERGEN, P.F.; POULTON; P.R. \& EVERSHED, R.P. Organic geochemical studies of soils from the Rothamsted classical experiments-II, Soils from the Hoosfield Spring barley experiment treated with diferent quantities of manure. Org. Geochem., 28:11-26, 1998.

COOPER, J.E. \& BRAY, E.E. A postulated role of fatty acid in petroleum formation. Geochim. Cosmochim, 27:11231127, 1963.

DINEL, H.; SCHNITZER, M. \& MEHUYS, G.R. Soil lipids: Origin, nature, contents, decomposition and effect on soil physical properties. In: BOLLAG, J.M. \& STOTZKY, G., eds. Soil biochemistry. New York, Marcel Dekker, 1990. v.6. p.397-429.

EGLINTON, G. \& CALVIN, M. Chemical fossils. Sci. Am., 216:32-43, 1967.

EGLINTON, G. \& LOGAN, G.A. Molecular preservation. Phil. Trans. R. Soc. Lond. B, 333:315-328, 1991.

EVERSHED, R.P.; BETHELL, P.H.; REYNOLDS, P. \& GOAD, L.J. Molecular markers of manuring: Analysis of modern experimental material and archaeological potential. J. Archaeol. Sci., 24:485-495, 1997.

FOSSARI, T.D. A população pré-colonial Jê na paisagem da Ilha de Santa Catarina. Florianópolis, Universidade Federal de Santa Catarina, 2004. 339p.

GLASER, B.; BALASHOV, E.G.; HAUMAIER L.; GUGGENBERGER, G. \& ZECH, W. Black carbon in density fractions of anthropogenic soils of the Brazilian Amazon region. Org. Geochem., 31:669-678, 2000.

GOOSSENS, H.; IRENE, W.; RIJPSTRA, C.; DÜREN, R.R. \& De LEEUW, J.W. Bacterial contribution to sedimentary organic matter; a comparative study of lipid in bacteria and recent sediments. Adv. Org. Geochem., 10:683-696, 1986.

GUGGENBERGER, G. \& ZECH W. Soil organic matter composition under primary forest, pasture, and secondary forest succession, Region Huetar Norte, Costa Rica. For. Ecol. Manag., 124:93-104, 1999.

HANSEL, F.A.; MIRESKI, S.L.; MADUREIRA, L.A.S. \& FOSSARI, T.D. Arqueologia biomolecular: Passos preliminares para interpretação sobre a origem dos resíduos orgânicos preservados em fragmentos de cerâmica pré-colonial no Brasil. Quim. Nova, 29:422-428, 2006.

HEDGES, J.I. \& OADES, J.M. Comparative organic geochemistry of soils and marine sediments. Org. Geochem., 27:319-361, 1997. 
HITA, C.; PARLANTI, E.; JAMBU, P.; JOFFRE, J. \& AMBLÈS, A. Triglyceride degradation in soil. Org. Geochem., 25:1928, 1996.

JAMBU, P.; AMBLÈS, A.; DINEL, H. \& SECOUET, B. Incorporation of natural hydrocarbon from plant residues into an hydromorphic humic podzol following afforestation and fertilization. J. Soil Sci., 42:629-636, 1991.

JAMBU, P.; AMBLÈS, A.; JACQUESY, J.C.; SECOUET, B. \& PARLANTI, E. Incorporation of natural alcohols from plant residues into a hydromorphic forest podzol. J. Soil Sci., 44:135-146, 1993.

JAMBU, P.; AMBLÈS, A.; MAGNOUX, P. \& PARLANTI, E. Effects of addition of clay minerals on the fatty acids fraction of a Podzol soil. Eur. Soil Sci., 46:187-192, 1995.

KAISER, K. \& GUGGENBERGER, G. The role of DOM sorption to mineral surfaces in the preservation of organic matter in soils. Org. Geochem., 31:711-725, 2000.

KERN, D.C. Geoquímica e pedogeoquímica em sítios arqueológicos com terra preta na floresta nacional de Coxiuamã (Portel - PA). Belém, Universidade Federal do Pará, 1996. 124p.

KERN, D.C. \& KÄMPF, N. O efeito de antigos assentamentos indígenas na formação de solos com terra preta arqueológicas na região de Oriximiná - PA. R. Bras. Ci. Solo, 13:219-225, 1989.

KOLATTUKUDY, P.E. Biopolyester membranes of plants: Cutin and suberin. Science, 208:990-1000, 1980.

MACKENZI, A.S.; BRASSEL, S.C.; EGLINTON, G. \& MAXWELL, J.R. Chemical fossils: The geological fate of steroids. Science, 217:491-217, 1982.

MATER L.; ALEXANDRE, M.R.; HANSEL, F.A. \& MADUREIRA, L.A.S. Assessment of lipid compounds and phosphorus in mangrove sediments of Santa Catarina Island, SC, Brazil. J. Braz. Chem. Soc., 15:725-734, 2004.

NAAFS, D.F.W. \& van BERGEN, P.F. A qualitative study on the chemical composition of ester-bound moieties in an acidic andosolic forest soil. Org. Geochem., 33:189-199, 2002.
NES, D.W.; LOPEZ, M.; ZHOU, W.; GUO, D.; DOWD, P.F. \& NORTON, R.A. Sterol utilisation and metabolism by Heliothis zea. Lipids, 32:1317-1323, 1997.

NIEROP, K. Origin of aliphatic compounds in a forest soil. Org. Geochem., 29:1009-1016, 1998.

SHIFFER, M.B. Formation processes of the archaeological records. Arizona, University of Arizona Press, 1987. 280p.

SIMPSON, I.A.; DOCKRILL, S.J.; BULL, I.D. \& EVERSHED, R.P. Early anthropogenic soil formation at Tofts Ness, Sanday, Orkney. J. Archaeol. Sci., 25:729-746, 1998.

SVOBODA, J.A. \& THOMPSON, M.J. Steroids. In: KERKUT, G.A. \& GILBERT, L.I., eds. Comprehensive insect physiology, biochemistry and pharmacology. Oxford, Pergamon Press, 1985. v.1. p.137-175.

TISSOT, B.P \& WELTE, D.H. Petroleum formation and ocurrence. 2.ed. Berlin, Springer-Verlag, 1984. 699p.

van BERGEN, P.F.; BULL, I.D.; POULTON, P.R. \& EVERSHED, R.P. Organic geochemical studies of soils from the Rothamsted classical experiments: I Total lipid extracts, solvent insoluble residues and humic acids from Broadbalk Wilderness. Org. Geochem., 26:117-135, 1997.

van BERGEN, P.F.; NOTT, C.J.; BULL, I.D.; POULTON, P.R. \& EVERSHED, R.P. Organic geochemical studies of soils from the Rothamsted classical experiments. IV Preliminary results from a study of the effect of soil $\mathrm{pH}$ on organic matter decay. Org. Geochem., 29:1779-1795, 1998.

WALTON, T.J. Wax, cutin and suberin. In: HARWOOD, J.L. \& BOWYER, J.R., eds. Biochemistry methods in plant. San Diego, Academic Press, 1990. v.4. p.105-158.

ZWIRTES, I.R. Uso da geocronologia e da distribuição de lipídios e fósforo na reconstituição histórica dos sedimentos da Lagoa da Conceição. Florianópolis, Universidade Federal de Santa Catarina, 2003. 69p. 